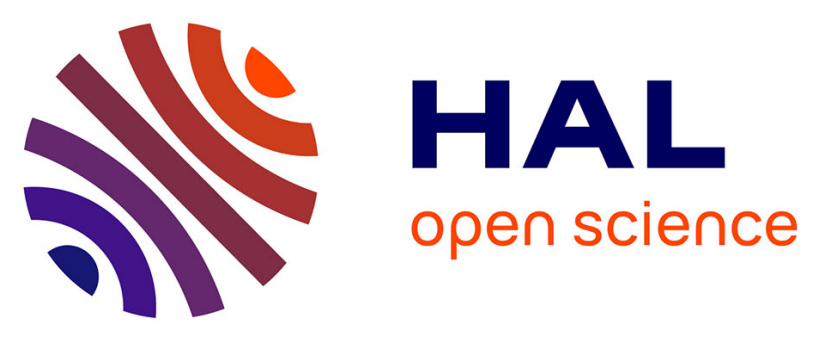

\title{
Changes in Sexual Behaviors in Men Who Have Sex with Men: A Comparison Between the Double-Blind and Open-Label Extension Phases of the ANRS-IPERGAY Trial
}

\author{
Marion Di Ciaccio, Luis Sagaon-Teyssier, Mohamed Mimi, Marie \\ Suzan-Monti, Christel Protiere, Daniela Rojas Castro, Laurence Meyer, Cécile \\ Tremblay, Christian Chidiac, Catherine Capitant, et al.
}

\section{- To cite this version:}

Marion Di Ciaccio, Luis Sagaon-Teyssier, Mohamed Mimi, Marie Suzan-Monti, Christel Protiere, et al.. Changes in Sexual Behaviors in Men Who Have Sex with Men: A Comparison Between the Double-Blind and Open-Label Extension Phases of the ANRS-IPERGAY Trial. AIDS and Behavior, 2020, 24 (11), pp.3093-3106. 10.1007/s10461-020-02864-8 . inserm-03202142

HAL Id: inserm-03202142 https://www.hal.inserm.fr/inserm-03202142

Submitted on 19 Apr 2021

HAL is a multi-disciplinary open access archive for the deposit and dissemination of scientific research documents, whether they are published or not. The documents may come from teaching and research institutions in France or abroad, or from public or private research centers.
L'archive ouverte pluridisciplinaire HAL, est destinée au dépôt et à la diffusion de documents scientifiques de niveau recherche, publiés ou non, émanant des établissements d'enseignement et de recherche français ou étrangers, des laboratoires publics ou privés. 


\section{AIDS and Behavior}

\section{Changes in sexual behaviors in men who have sex with men: a comparison between the double-blind and open-label extension phases of the ANRS-IPERGAY trial \\ --Manuscript Draft--}

Manuscript Number:

Full Title:

Article Type:

Keywords:

Corresponding Author:

Corresponding Author Secondary
Information:

Corresponding Author's Institution:

Corresponding Author's Secondary Institution:

First Author:

First Author Secondary Information:

Order of Authors:

Order of Authors Secondary Information:

Funding Information:

Abstract:
AlBE-D-19-00398R2

Changes in sexual behaviors in men who have sex with men: a comparison between the double-blind and open-label extension phases of the ANRS-IPERGAY trial

Original Research

HIV risk management; on-demand PrEP; behaviors; MSM; ANRS-IPERGAY trial.

Marion Di Ciaccio

INSERM

Marseille, FRANCE

INSERM

Marion Di Ciaccio

Marion Di Ciaccio

Luis Sagaon-Teyssier

Mohamed Mim

Marie Suzan-Monti

Christel Protiere

Daniela Rojas Castro

Laurence Meyer

Cécile Tremblay

Christian Chidiac

Catherine Capitant

Marie Préau

Jean Michel Molina

Bruno Spire

\begin{tabular}{|l|l|}
\hline $\begin{array}{l}\text { ANRS } \\
(\mathrm{x})\end{array}$ & $\begin{array}{l}\text { Mrs Marion Di Ciaccio } \\
\text { Not applicable }\end{array}$ \\
\hline $\begin{array}{l}\text { the Canadian HIV Trials Network } \\
(\mathrm{x})\end{array}$ & Not applicable \\
$\begin{array}{l}\text { the Fonds de dotation Pierre Bergé pour } \\
\text { la Prévention } \\
(\mathrm{x})\end{array}$ & Not applicable \\
\hline $\begin{array}{l}\text { SIDACTION } \\
(\mathrm{x})\end{array}$ & Not applicable \\
\hline $\begin{array}{l}\text { the Bill and Melinda Gates Foundation } \\
(\mathrm{x})\end{array}$ & Not applicable \\
\hline
\end{tabular}

Pre-Exposure Prophylaxis (PrEP) is changing the landscape of HIV prevention, and 


\section{Response to Reviewers:}

may bring changes in sexual behaviors. The double-blind phase (DBP) and open-label extension (OLE) study of the ANRS-IPERGAY trial allowed us to assess changes in sexual behavior of men who have sex with men (MSM) taking sexual activity-based (i.e., on-demand) PrEP. Generalized Estimating Equation (GEE) models found a significant decrease in the number of sexual partners (Coefficient [CI95\%], p-value; $0.37[-0.70--0.04], p=0.03$ ) between the DBP and OLE as well as in the number of sexual relations $(-0.25[-0.49-0.00], 0.04)$. GEE estimates also showed that respondents' most recent sexual relation was less likely to have been with an unknown casual partner during the OLE than during the DBP (Odds Ratio [CI95\%], p-value: $0.75[0.62-0.92], 0.005)$. Furthermore, they showed an increase in the proportion of condomless anal sex in the OLE (1.32[1.04-1.67], 0.02), a decrease in the proportion of 'suboptimal PrEP adherence' over time (0.75[0.58-0.97], $p=0.03)$, a decrease in PrEP only use (0.73[0.55-0.96], 0.03) and in both PrEP and condom use over time $(0.70[0.51-0.95], 0.02)$ and finally, a decrease in alcohol consumption between the DBP and OLE (0.74[0.61-0.90], 0.002).

We observed both protective and risky behaviors in terms of HIV and STI risk after ondemand PrEP uptake in the OLE phase. Our findings are consistent with results from previous PrEP trials.

\section{Dear Editor,}

We would like to resubmit our manuscript entitled "Changes in sexual behaviors in men who have sex with men: a comparison between the double-blind and open-label extension phases of the ANRS-IPERGAY trial" for publication in AIDS and Behavior. We have taken into account all the comments made by the reviewers. A separate document explains the changes made to the manuscript in greater detail.

Neither this manuscript nor the data therein have been previously published, nor are they under consideration for publication elsewhere. All authors have read and approved the content of the submitted manuscript and have no conflict of interest to declare.

We hope that this manuscript will be suitable for publication in AIDS and Behavior and we look forward to receiving recommendations and suggestions from your Editorial Board.

Yours faithfully,

Marion Di Ciaccio


Marion Di Ciaccio, PhD Student

GRePS- University Lyon 2

UMR912 SESSTIM - INSERM-IRD-University Aix Marseille

Research Team SanteRCom - Health and community research

IHU, 19-21 Boulevard Jean Moulin - 13005 Marseille, France

Tel: +33 (0)626705132 / marion.di-ciaccio@inserm.fr

Marseille, 07 April 2020

\section{Dear Editor,}

We would like to resubmit our manuscript entitled "Changes in sexual behaviors in men who have sex with men: a comparison between the double-blind and open-label extension phases of the ANRSIPERGAY trial" for publication in AIDS and Behavior. We have taken into account all the comments made by the reviewers. A separate document explains the changes made to the manuscript in greater detail.

Neither this manuscript nor the data therein have been previously published, nor are they under consideration for publication elsewhere. All authors have read and approved the content of the submitted manuscript and have no conflict of interest to declare.

We hope that this manuscript will be suitable for publication in AIDS and Behavior and we look forward to receiving recommendations and suggestions from your Editorial Board.

Yours faithfully,

Marion Di Ciaccio 


\section{Dear Dr. Di Ciaccio,}

The review of your revised manuscript (AIBE-D-19-00398R1) resubmitted for publication in AIDS and Behavior. I sent your paper back to the original reviewers. The response to your revision was mostly favorable. The reviewers had additional suggestions. From my own reading of your revision, I agree with the reviewers and I believe that your paper is much closer to publishable form. I also believe that your paper will benefit from additional careful edit.

I can therefore offer provisional acceptance of your paper based on its current form. However, your paper will not be publishable unless it addresses the most recent comments and is formatted correctly for the journal. Authors once more and be sure that your text, references, and tables/figures are properly formatted. Please provide a point-by-point response to remaining comments and submit your next version as a clean copy, without any tracked changes.

AIDS and Behavior now offers the opportunity to publish abstracts for articles in English and Spanish. Although not required, I am hoping that you will take advantage of this chance to broaden access of your work. If you would like to include your Abstract in Spanish, please be sure that your Abstract is in the proper format and finalized. Be sure to remove all subheadings from the Abstract so that it reads as a continuous narrative of no more than 150 words in English. Then translate your final Abstract into Spanish. Upload the English version in the Editorial Manager System step for Abstracts and include both the English and Spanish versions in your Manuscript file that you upload into the system. The two abstracts should be placed together, first the English followed by the Spanish on a separate pages. Label the Spanish version "Resumen".

Please carefully proof read your paper before resubmitting. You might also take this one more opportunity to be sure that the data are all reported correctly in your paper.

Please resubmit your revision within 2 months of receipt of this correspondence.

Reviewer \#1: Overall, the revised manuscript is significantly improved, and the writing is easier to follow. The topic remains important, and the findings have potential impact on PrEP implementation strategies. However, there are a number of issues that still need to be addressed.

1. The introduction could be further strengthened by a more detailed description of the social context specially applied to PrEP use such as risk compensation. The addition of references is great, but it still needs to be more explicitly stated what you mean by social context, for example, risk compensation has been a major issue identified by critics of PrEP, and your manuscript really addresses this and provides important information that PrEP does not increase risk. This is worthwhile of a discussion that is currently absent in the introduction.

We added information about risk compensation in terms of PrEP use in the introduction section ( $p 3$ I 34-51) to better explain what we mean by social context.

2. In the methods, can you briefly describe the OLE phase? Was it the same procedures as DBP or were there more provisions for a "real-world context?" Why were new participants added? Also, you should state that you only included participants that were in both studies- it is confusing that the analysis numbers don't match the numbers described in the methods.

We added more information concerning the OLE phase in the method section (p 8 I166-172). The only difference between the DBP and the OLE was the suppression of the placebo arm following the proof of on-demand PrEP effectiveness. New inclusions were permitted for the OLE phase in order to increase the reliability of the study. It is worth pointing out that PrEP was not yet authorized for MSM in France at the time of this study, so extending the study's reach to include new participants 
also brought PrEP to a larger number of people. We also specified in the statistical analysis section (p12 1266-268) that analyses were conducted only on participants enrolled in both phases.

3. Were questions about drug and alcohol use specifically related to sexual activity (e.g. used during sexual intercourse)? This is not stated in the description of the outcomes in the methods, although in the discussion it states (line 356): "decrease in alcohol consumption during sexual intercourse." Please clarify in the methods.

Yes, drug and alcohol use were specifically related to sexual activity. We now specify this in the outcome section (p10 I209 and 212).

4. What is the justification for the comparison between DBP \& OLE and DBP only? Is there something particularly compelling about the 67 participants that did not continue on to DBP that is relevant to the present study? I would consider removing it, since the primary outcomes focus only on those that were in both studies, and the DBP only data in Tables I add confusion. If it is important to note differences between these groups 1) state why this is important in the methods, and 2) maybe just mention it in the text rather than include in the table.

We compared the 67 participants who left the trial before the OLE with the 332 participants who completed both phases in order to verify that the former did not have a greater number of HIV risky sexual behaviors than the latter, as such a situation could have biased our results.

To take into account your comment, we removed data about these 67 participants from Table 1 and added the statistical analysis used for the comparison in the methods section, as well as a sentence indicating why this was important to compare these samples (p12 1269-272).

5. It is a bit misleading to say "We observed no obvious increase of HIV risky behaviors after onset of on-demand PrEP initiation," (lines 366-369), and this is inconsistent with the findings in the results and the previous paragraph (lines 357-360) that state that you did find increases in risky behavior. This paragraph needs to be revised to be consistent and accurate with the study findings. The data the authors highlight in the discussion seem a bit cherry-picked. That is, there seems to be a focus on decreases in risky behavior (alcohol consumption, casual partners) and less focus on behaviors that did not change or increased (CAS, drug use, multiple partners). The discrepancies between the nonlongitudinal results (Table II) and the longitudinal results are still not fully explained, and the statement in line 424 "...globally our results confirmed the absence of additional risk taking" implies the nonlongitudinal comparisions (Table II) that did find differences in risky behavior between DBP and OLE. This discrepancy needs to be addressed, and perhaps the discussion needs to include a fuller interpretation of the results.

We deleted the sentence "We observed no obvious increase of HIV risky behaviors after onset of ondemand PrEP initiation" and now provide a more in-depth discussion of our results. More specifically, we now discuss the evolution of PrEP adherence from GEE results in light of PrEP persistence issues. We also discuss the difference in results between non-longitudinal and GEE models, given that the latter took into account time trends during both phases, while the former only focused on changes between both phases (p17 I387-399 and p 18 1400-408).

We added a paragraph about the sexual factors which did not change with the use of PrEP (specifically, drug use in the sexual context and sexual intercourse with multiple or known casual partners) (p18 1409-411).

Furthermore, we deleted "...globally our results confirmed the absence of additional risk taking" and now present protective and risky sexual behaviors regarding HIV and STI after PrEP initiation in the study (p19 1432-443).

6. There is a fairly substantial section of the discussion focused on STIs, but this is not a result that is provided and seems out of context and is really just reporting results from a previous paper. It would be a stronger discussion to focus on the findings from the present study. 
We shortened the section focused on STIs (p18-19 1417-431) in order to develop discussion about other results, especially regarding risk compensation (p20 1461-467).

7. There remains a lack of discussion on how these data might inform future roll-outs of PrEP cohort studies, and the implications of the findings in successful implementation strategies for PrEP. Based on our results, we now develop recommendations which should be taken into account for future PrEP cohort studies, mainly concerning STI prevention and PrEP persistence (p21 1479-495).

Minor edits

1. Overall, the writing is much more clear, but it could still benefit from careful proofreading.

2. Write out OLS and OLE the first time they are used in the manuscript (line 62). Also, it is not clear what the difference between OLE and OLS studies are in the introduction.

We have written out what OLS and OLE mean in the manuscript (p4 179 and p 5 180) and we now explain the difference between both (p5 180-82). The main difference is that OLE refers to an openlabel phase in a clinical trial which follows a double-blind phase, while OLS is an open-label study (cohort) in a context outside a clinical trial.

3. The statements starting after the colon in line 279 all end in periods even though they are part of the same sentence. This makes it look like sentences that have been cut off. Please revise the format.

We changed the periods for semi-colons.

4. Define "IST risk" line 359

We modified the term for "STI incidence"

5. The term sexual intercourses is not typically plural, and the use of sexual intercourses is awkward in multiple places.

We have decided to use the terms "sexual relation" and "sexual relations" almost exclusively throughout the manuscript. 


\section{Changes in sexual behaviors in men who have sex with men: a comparison between the double-blind and open- label extension phases of the ANRS-IPERGAY trial}

Marion Di Ciaccio ${ }^{1,2}$, Luis Sagaon-Teyssier ${ }^{1,3}$, Mohamed Mimi ${ }^{1,3}$, Marie Suzan-Monti ${ }^{1,3}$, Christel Protiere ${ }^{1,3}$, Daniela Rojas Castro ${ }^{1,2,4,5}$, Laurence Meyer ${ }^{6}$, Cécile Tremblay ${ }^{7}$, Christian Chidiac $^{8}$, Catherine Capitant ${ }^{9}$, Marie Préau ${ }^{2,1}$, Jean Michel Molina ${ }^{9}$, Bruno Spire ${ }^{1,3} \&$ the ANRS IPERGAY Study Group

1. Aix Marseille Univ, INSERM, IRD, SESSTIM, Sciences Economiques \& Sociales de la Santé \& Traitement de l'Information Médicale, Marseille, France,

2. Groupe de Recherche En Psychologie Sociale (GRePS), Université Lyon 2, Lyon, France,

3. Observatoire Régional de la Santé Provence-Alpes-Côte d'Azur, Marseille, France,

4. AIDES (Mission Innovation Recherche Expérimentation), Pantin, France,

5. Coalition Internationale Sida, Pantin, France,

6. INSERM SC 10 US 19, Villejuif, France,

7. Centre Hospitalier de l'Université de Montréal-Hôtel Dieu, Montréal, Canada,

8. Département des maladies infectieuses, Hôpital de la Croix Rousse, Centre Hospitalier et Universitaire de Lyon, Lyon, France,

9. Département des maladies infectieuses, Hôpital Saint-Louis, Assistance Publique Hôpitaux de Paris, Université de Paris Diderot Paris 7, INSERM U941, Paris, France

Corresponding author:

Marion Di Ciaccio

marion.di-ciaccio@inserm.fr

$+33626705132$ 


\section{Competing interests}

JMM reports receiving support as an adviser for Gilead Sciences, Merck, Janssen, BristolMyers Squib (BMS), and ViiV Healthcare, as well as research grants from Gilead Sciences and Merck. BS reports receiving support as an adviser for Gilead Sciences, Merck, Janssen, and BMS, as well as research grants from Gilead Sciences and Merck. CCh reports receiving support as an adviser for Gilead, Pfizer, Janssen, and Astellas. CT reports receiving support from Gilead Sciences and Pfizer. All other authors declare no competing interests.

\section{Authors' contributions}

MDC implemented this work under the supervision of LST and BS. MDC, MM and LST led the analysis. The manuscript was written collaboratively between MDC, LST, MSM, CP and BS, with input from DRC, LM, MP and JMM. CT, CCh and CC provided ongoing support to design and perform data collection throughout the cohort study. All authors approved the final manuscript.

\section{Acknowledgements}

We would like to thank all the study's participants who dedicated their time to this research for the benefit of their community. We also thank the AIDES community advocacy group and their community peer counsellors who made the study possible, through their availability and continuous interaction with the participants and study staff at study sites and, most importantly, outside the hours of scheduled visits. Our thanks also to Jude Sweeney for the English revision and editing, and to Bakridine Mmadi Mrenda for his contribution to the statistical analyses. This work was sponsored by the ANRS (France Recherche Nord \& Sud Sida-HIV Hépatites) and funded by the ANRS, the Canadian HIV Trials Network, the Fonds de dotation Pierre Bergé pour la Prévention - SIDACTION, and the Bill and Melinda Gates Foundation. MDC is the recipient of a doctoral fellowship from the ANRS.

The ANRS IPERGAY study group: J.-M. Molina (coordinator), C. Capitant, B. Spire, G. Pialoux, L. Cotte, I. Charreau, C. Tremblay, J.-M. Le Gall, E. Cua, A. Pasquet, F. Raffi, C.

Pintado, C. Chidiac, J. Chas, P. Charbonneau, C. Delaugerre, M. Suzan-Monti, B. Loze, J. Fonsart, G. Peytavin, A. Cheret, J. Timsit, G. Girard, N. Lorente, M. Préau, J.F. Rooney, 
M.A. Wainberg, D. Thompson, W. Rozenbaum, V. Doré, L. Marchand, M.-C. Simon, N. Etien, J.-P. Aboulker, L. Meyer, and J.-F. Delfraissy.

Participating hospitals and investigators: Paris St-Louis: C. Pintado, B. Loze, C. Delaugerre, P. Charbonneau, C. Gatey, D. Ponscarme, P. Penot, L. Niedbalski, R. Veron, J. Delgado, E. Dalle, S. Parlier, I. Madelaine, J. Fonsart, M. Danet, N. Mahjoub, N. Mezreb, K. Moudachirou, S. Morel, G. Conort, F. Lorho, M. Meunier, W. Rozenbaum, J.M. Molina; Paris Tenon: J. Chas, C. Monfort, J. Foucoin, B. Boissavy, S. Cousseau, S. Huon, M. Danet, A. Djessima, V. Berrebi, A. Adda, S. le Nagat, L. Zarka, J. Berdougo, G. Pialoux; Lyon: C. Chidiac, N. Mzoughi, F. Clement, A. Decouty, C. Chapolard, M. Godinot, C. Adouardgroslafeige, J. Koffi, A. Pansu, A. Becker, S. Pailhes, F. Bonnet, F. Jeanblanc, C. Brochier, X. Teruin, S. Rouby, L. Gilly, L. Cotte; Montréal: C. Beauvais, P. Arlotto, C. Fortin, A. Talbot, A. Chamberland, A. McKenzie, M. Blanchette, R; Rousseau, K. Montheuth, D. Thompson, M. Morin, M. Wainberg, C. Tremblay ; Nice: C. Etienne, F. Tolonin, S. Breaud, V. Péchenot, S. Bagge, T. Cepitelli, PM. Roger, E. Rosenthal, E. Cua; Tourcoing: A. Cheret, P. Cornavin, S. Vandamme, J. Lambec, N. Dumon, O. Leclanche, T. Huleux, R. Biekre, O. Robineau, H. Melliez, H. Bazus, A. Pasquet; Nantes: C. Bernaud, M. Besnier, B. Bonnet, N. Hall, M. Cavellec, H. Hue, L. Larmet, M. Colas, R. Choquet, F. Raffi. 


\section{Abstract}

2 Pre-Exposure Prophylaxis (PrEP) is changing the landscape of

3 HIV prevention, and may bring changes in sexual behaviors. The

4 double-blind phase (DBP) and open-label extension (OLE)

5 study of the ANRS-IPERGAY trial allowed us to assess changes

6 in sexual behavior of men who have sex with men (MSM) taking

7 sexual activity-based (i.e., on-demand) PrEP. Generalized

8 Estimating Equation (GEE) models found a significant decrease

9 in the number of sexual partners (Coefficient [CI95\%], p-value;

$10-0.37[-0.70--0.04], \mathrm{p}=0.03$ ) between the DBP and OLE as well

11 as in the number of sexual relations $(-0.25[-0.49-0.00], 0.04)$.

12 GEE estimates also showed that respondents' most recent sexual

13 relation was less likely to have been with an unknown casual

14 partner during the OLE than during the DBP (Odds Ratio

15 [CI95\%], p-value: 0.75[0.62-0.92], 0.005). Furthermore, they

16 showed an increase in the proportion of condomless anal sex in

17 the OLE (1.32[1.04-1.67], 0.02), a decrease in the proportion of

18 'suboptimal PrEP adherence' over time (0.75[0.58-0.97],

$19 \mathrm{p}=0.03)$, a decrease in PrEP only use $(0.73[0.55-0.96], 0.03)$ and

20 in both PrEP and condom use over time (0.70[0.51-0.95], 0.02)

21 and finally, a decrease in alcohol consumption between the DBP

22 and OLE (0.74[0.61-0.90], 0.002).

23 We observed both protective and risky behaviors in terms of

24 HIV and STI risk after on-demand PrEP uptake in the OLE

25 phase. Our findings are consistent with results from previous 
26 PrEP trials.

27 Keywords: HIV risk management, PrEP, behaviors, MSM,

28 ANRS-IPERGAY trial.

29 


\section{Introduction}

31 In recent years, Pre-Exposure Prophylaxis (PrEP) has emerged

32 as one of the most important innovations in HIV prevention for

33 high-risk HIV-negative people, especially men who have sex

34 with men (MSM) (1-3). HIV prevention innovation is regularly

35 associated with the question of "risk compensation" (RC),

36 whereby individuals may take more risks based on the belief that

37 they are protected from infection (e.g., because of condom use,

38 voluntary male circumcision, etc.) (4-6). In the context of PrEP,

39 this translates into a possible increase in condomless sex or in

40 the number of partners, which in turn could negatively impact

41 sexually transmitted infections (STI) incidence. Social norms,

42 moral judgment and the sexuality of people at high risk of HIV

43 infection are all factors in $\mathrm{RC}$ and in reticence to provide PrEP

44 access $(7,8)$. Indeed, the editorial, "PrEP why we are waiting",

45 published in The Lancet HIV, illustrates the moral debate

46 surrounding PrEP use and the interaction of social norms with

47 decision-making regarding health (22). More specifically, the

48 authors explained that the first studies on PrEP were focused on

49 its effectiveness and cost, not on normative aspects such as MSM

50 responsibility to use condoms or the important effect of no

51 longer being afraid of HIV infection during sex (22). The very

52 different stances taken by MSM and medical communities

53 regarding PrEP initiation underline that it is not simply a

54 biomedical preventive tool but can also be considered a social 
55 object (9-11) whose adoption is influenced by social and

56 environmental factors $(12,13)$. The psychosocial approach to

57 health hypothesizes that health behaviors (e.g., preventive and

58 sexual behaviors) are influenced by context at the micro/meso

59 (e.g., attitudes and social norms related to sexuality and

60 prevention strategies in social groups which people belong to)

61 and macro (e.g., a culture's attitudes and ideologies toward

62 health and sexuality; the availability of and access to prevention

63 tools) levels (14).

64 In this context, we hypothesized that making PrEP available

65 leads to a change in the field of HIV prevention, which in turn

66 may bring about a change in sexual and preventive behaviors.

67 Accordingly, it is important to study whether sexual behaviors

68 are modified by PrEP initiation and whether they change over

69 time.

70 In the double-blind phase (DBP) of the US CDC Safety Study (a

71 randomized clinical PrEP trial with quarterly follow-up over 2

72 years), participants reported fewer partners and less condomless

73 anal sex (CAS) (15). The DBP of the ANRS-IPERGAY trial

74 showed no increase in risky sexual practices (16). During the

75 DBP of the iPrEx trial (quarterly follow-up over 3 years), no

76 increase in receptive CAS or syphilis incidence was observed

77 (17,18). The absence of reported changes in double-blind studies

78 may be due to participants not modifying their behavior because

79 they know they may be taking a placebo (18). As open-label 
80 extension (OLE) and open-label (OLS) studies (the former

81 following DBP in clinical trials, while the latter are performed

82 in non-clinical contexts) both reflect near real-world situations,

83 they constitute excellent research opportunities to determine

84 whether changes in sexual behaviors occur over time in

85 participants who initiate PrEP. Results from the OLE study of

86 the iPrEx trial (quarterly follow-up over 3 years) showed no

87 increase in receptive CAS or syphilis incidence $(17,18)$, while

88 mixed results were found in the OLS PROUD trial, which

89 compared participants randomized into an 'immediate PrEP'

90 arm with those randomized into a 'one-year deferred PrEP' arm.

91 More specifically, a larger proportion of respondents in the

92 former reported CAS, yet no difference was observed between

93 both arms concerning the number of sexual partners (2).

94 Furthermore, objective indicators of CAS, including the

95 incidence of rectal gonorrhea and chlamydia infections, were not

96 different between both arms. Despite the longitudinal dimension

97 of the PROUD trial, the changes in sexual behaviors were only

98 analyzed for one time-point (12 months). The OLS US PrEP

99 Demonstration Project showed a decrease in the mean number

100 of anal intercourse partners and no change in the proportion of

101 CAS during follow-up (quarterly follow-up over one year) (19).

102 STI incidence also remained stable (19). To summarize, results

103 from OLE and OLS studies to date have not shown any clear

104 changes in MSM risky sexual behaviors after PrEP initiation. 
105 With regards to real-world settings, results are mixed. A clinical

106 PrEP program in Rhode Island showed an increase in the number

107 of CAS partners 6 months after PrEP initiation compared with

108 baseline data (20) while findings from a different clinical setting

109 indicated no increase in either STI incidence or the number of

110 sexual partners after PrEP initiation (bi-annual follow-up over

111 one year) (21).

112 Apart from the iPrEx trial, no study to date has collected

113 longitudinal data about changes in sexual behaviors before and

114 after PrEP initiation. Moreover, no OLE or OLS study has

115 evaluated changes in sexual behaviors in MSM who take sexual

116 activity-based PrEP (i.e., on-demand PrEP). The efficacy of

117 sexual activity-based PrEP in MSM was shown in the ANRS-

118 IPERGAY trial which involved a longitudinal follow-up of

119 participants in both the DBP and OLE phases $(3,22)$. Unlike

120 daily PrEP, sexual activity-based PrEP requires individuals to

121 assess risks before sexual relations. This may prompt MSM to

122 reappraise their preconceptions of the risks involved over time

123 (i.e., a change in risk perception), leading in turn to changes in

124 their sexual behaviors.

125 The present paper aimed to assess changes in sexual behaviors

126 of MSM between the DBP and OLE phases of the ANRS-

127 IPERGAY trial. Although previous studies of sexual behaviors

128 in PrEP trials primarily used only two indicators (the proportion

129 of CAS and the number of partners), in order to guarantee a more 
130 holistic approach, we chose to study changes for a much wider

131 set of behavioral factors, described in detail in the methods

132 section below.

\section{Methods}

\section{ANRS-IPERGAY trial design}

135 The ANRS-IPERGAY trial, conducted in France (Paris, Nantes,

136 Lyon, Lille and Nice) and Canada (Montreal), consisted in

137 providing sexual activity-based PrEP to high-risk MSM (3).

138 Inclusion criteria were HIV-negative status, being at least 18

139 years old, being a male or transgender female who had sex with

140 men, and being at high risk of HIV infection (defined as a history

141 of CAS with at least two partners during the previous 6 months)

142 (3). At baseline, participants completed a questionnaire covering

143 socio-demographic characteristics and sexual behaviors. The

144 trial was conducted in partnership with the community-based

145 association AIDES, which identified and enrolled participants,

146 thanks to its members' proximity to the MSM community. At

147 follow-up visits (two-monthly), participants benefited from one-

148 to-one, tailored, risk-reduction counselling provided by a peer

149 counsellor. As part of the trial, they were provided condoms and

150 lubricants, and were regularly tested for HIV and other sexually

151 transmitted infections free of charge (STI) (3). During

152 counselling visits, peer counsellors encouraged PrEP uptake as

153 part of combined prevention (e.g., PrEP in conjunction with

154 condom use). The PrEP treatment schedule was as follows: two 
155 pills (TDF-FTC or placebo) 2 to 24 hours before sexual relations,

156 followed by a third and fourth pill 24 and 48 hours after the first

157 dose, respectively. For participants who had very frequent sexual

158 relations, the schedule was one pill per day for each day when

159 sexual relations occurred, then one pill 24 and 48 hours after

160 their most recent sexual relation $(3,22)$. The randomized DBP

161 started in February 2012, and thanks to the reduction observed

162 in HIV incidence between the two arms, the placebo arm was

163 discontinued in November $2014(3,22)$. The trial then continued

164 as an OLE study until June 2016. MSM who had not participated

165 in but were eligible for the DBP could be included in the OLE

166 sample, depending on eligibility. The OLE phase included 29

167 new participants. The only difference between the DBP and the

168 OLE was the suppression of the placebo arm following the proof

169 of on-demand PrEP effectiveness. New inclusions were

170 permitted for the OLE phase in order to provide PrEP access to

171 a larger sample of MSM in France (a sub-population for which

172 PrEP was not yet authorized in France at the time of this study).

173 During the DBP and OLE phases, online questionnaires were

174 completed every 2 months covering socio-demographic

175 characteristics, alcohol and recreational drug use, sexual

176 behaviors, and PrEP adherence during participants' most recent

177 sexual relation. Questionnaires were sent through an online link

17810 days before the scheduled follow-up visit. Participants had

179 one month to complete them before the online link expired. 
180 When a delay in filling in a questionnaire was detected, two

181 reminders were sent by email, the first 5 days before the

182 scheduled follow-up visit and the second before the online link

183 expired. Participants could fill in the questionnaires together

184 with the peer counsellor during the follow-up visit if they

185 wished. PrEP delivery was guaranteed irrespective of whether

186 the questionnaire was filled in or not.

187 The protocol (amended for the OLE study) was approved by

188 public health authorities and ethics committees in France

189 (Comité de Protection des Personnes, Paris, Ile de France IV)

190 and Canada (Comité d'éthique de la recherche, Montreal, QC).

191 All participants provided written informed consent to participate

192 in the DBP. All 361 participants of the OLE study provided oral

193 informed consent, with 353 (98\%) of them also providing

194 written consent.

195 Outcomes

196 At each bi-monthly visit (from M0 to M24 in the DBP, and from

197 M0 to M18 in the OLE), sexual behavior and prevention

198 strategies were assessed at each follow-up visit using the

199 following eight outcomes, two of which were continuous (i and

200 ii) and six of which concerned the most recent sexual relation (iii

201 to viii): (i) number of sexual relations during the previous 4

202 weeks; (ii) number of sexual partners during the previous 2

203 months; (iii) a 4-category outcome for the type of partner: main,

204 unknown casual, known casual or multiple; (iv) a dichotomous 
indicator for insertive/receptive CAS (yes= 1 and no $=0$ ); (v) a

206 4-category outcome for combined prevention: PrEP only,

207 condom use only, PrEP and condom use, and no PrEP or condom

208 use; (vi) a 6-category outcome for the use of the following

209 recreational drugs (in the context of sexual relations): ecstasy,

210 cocaine, poppers, GHB/GBL, Ketamine, Viagra; (vii) a

211 dichotomous indicator for alcohol consumption (in the context

212 of sexual relations) (yes $=1 / \mathrm{no}=0$ ) ; and (viii) a 3-category

213 outcome for PrEP adherence: correct use, no PrEP use, and

214 suboptimal use. 'Correct' use was defined as taking at least one

215 pill within 24 hours before sexual relations and one pill within

21624 hours after relations, 'no PrEP use' was defined as not taking

217 any pills within 48 hours either before or after the most recent

218 sexual relation, while 'suboptimal use' was defined as any other

219 use (3).

220 We hypothesized that investigating several behavioral factors

221 would provide a more holistic overview of the changes in sexual

222 behaviors and prevention strategies in the study population.

223 Although measures of plasma drug levels show whether

224 participants have been exposed to TDF-FTC, it is not clear if this

225 occurs before and after PrEP pill intake (22). Accordingly, we

226 were not able to use this variable to assess on-demand PrEP

227 schedule adherence. The iPrEx study showed that self-reporting

228 PrEP use was a strong predictor of concentration in plasma (23). 
229 Therefore, we used self-reported adherence to measure on-

230 demand PrEP adherence during the most recent sexual relation.

231 We were able to observe how PrEP uptake influenced study

232 participants' sexual behaviors by evaluating the following: CAS,

233 the number of partners, number of sexual relations, type of

234 sexual partner, and alcohol and recreational drug use before and

235 during sex.

236 Statistical analysis

237 Chi-square tests (dichotomous and categorical outcomes) and t-

238 tests (continuous outcomes) were performed to describe the

239 sociodemographic characteristics and sexual behaviors of

240 participants at inclusion in the DBP. The same tests were also

241 performed to compare outcomes between the DBP and OLE

242 phases.

243 We also implemented generalized estimating equation (GEE)

244 models to study changes over time over time in the study

245 population's sexual behaviors after PrEP initiation. The main

246 advantage of GEE models is that they take account of intra-

247 individual correlation in longitudinal settings, which allows

248 robust estimations of outcomes and associated variances $(24,25)$.

249 We used a negative binomial function for continuous outcomes,

250 a binary logistic function for dichotomous outcomes, and a

251 multinomial logistic function for outcomes with more than 2

252 categories. 
253 In line with our study's objectives, the GEE models were

254 adjusted according to the three following explanatory variables:

255 i) a dichotomous variable to investigate whether the outcomes 256 changed significantly between DBP and OLE phases, ii) time as 257 a continuous variable, to measure the overall changes in 258 outcomes over time and iii) a variable measuring the interaction 259 between time and the DBP/OLE indicator, which enabled us to 260 investigate whether changes over time occurred more during the 261 DBP or more during the OLE. Three GEE models were tested 262 for each outcome by adding the explicative variables one by one.

263 We used the Independence model Criterion (QIC) for the 264 goodness-of-fit in order to choose the model with the best 265 specification.

266 In line with our study's objectives, analyses were performed 267 only for the 332 participants who participated in both the DBP 268 and OLE.

269 To compare whether participants who left the trial after the DBP

270 phase $(n=67)$ were not at greater risk than those participating in

271 both phases $(\mathrm{n}=332)$ a comparison was performed using chi272 square/T test.

273 All analyses were performed using SAS 9.4 statistical software.

274 Results

275 Sample characteristics 
276 The present analyses were performed on the 332 participants

277 enrolled in both the DBP and OLE phases (Table 1),

278 corresponding to 4978 analyzable questionnaires.

279 Mean age was 35.8 years $(\mathrm{sd}=14.0)$ (Table 1). Most participants

280 self-defined as gay $(\mathrm{n}=305,91.9 \%)$, and only 10 as bisexual

281 (3.0\%). A majority (73.9\%) reported having an education level

282 equal to or higher than high-school diploma, while $84.6 \%$

283 reported being in active employment.

284 With regard to sex life, at DBP baseline, $41.9 \%$ reported having

285 a main partner. Of these, $61.3 \%$ had an HIV-negative main

286 partner. The mean number of sexual relations (in the previous 4

287 weeks) and of sexual partners (in the previous 2 months) was,

$28813(\mathrm{sd}=11.7)$ and $13.5(\mathrm{sd}=16.1)$, respectively. At baseline, $60.7 \%$

289 and 58.6\% reported CAS and PrEP use, respectively. A majority

$290(78.8 \%)$ reported sexual relations with partners other than a main

291 partner. Use of recreational drugs and alcohol consumption

292 before/during sex were reported by $36.7 \%$ and $12.6 \%$ of the

293 participants, respectively. No significant difference was

294 estimated between the 332 respondents who participated in both

295 the DBP and OLE phases, and those who left the trial after the

296 DBP phase $(n=67)$.

297 Comparative description of sexual behaviors and prevention

298 strategies between the DBP and OLE phases

299 No significant difference was reported between the DBP and

300 OLE in terms of the mean number of sexual relations during the 
301 previous 4 weeks $(13.2(\mathrm{sd}=15.9)$ vs $12.5(\mathrm{sd}=14.7) ; \mathrm{p}=0.11)$ or

302 the mean number of sexual partners during the previous 2

303 months (13(sd=16.1) vs 12.3(sd=19.3), $\mathrm{p}=0.20)$ (Table 2; Fig.1).

304 With respect to the most recent sexual relation, the following

305 results were found regarding changes in sexual behaviors

306 between the DBP and the OLE study:

307 i) a significant increase in the proportions of most recent sexual

308 relation with unknown casual partners $(48.0 \%$ in the DBP $v s$.

$30952.0 \%$ in the OLE, $\mathrm{p}<0.005)$ and most recent sexual relation

310 with main partners (41.1\% in the DBP vs. 58.9\% in the OLE,

$311 \quad \mathrm{p}<0.001)($ Table 2; Fig.2);

312 ii) a significant increase in the proportion of CAS (Table 2;

313 Fig.3) (42.2\% vs. 57.8\%, p<0.001);

314 iii) an increase in the proportions of reported 'correct' PrEP

315 adherence $(39.9 \%$ in DBP $v s .60 .1 \%$ in OLE, $\mathrm{p}<0.005)$ and

316 'suboptimal' PrEP adherence (48.1\% vs 51.9\%, p<0.001) (Table

317 2; Fig.4);

318 iv) a significant increase in the proportions of most recent sexual

319 relations with 'PrEP only' (39.6\% vs. 60.4\%, p<0.005) and with

320 'both PrEP and condom use' (48.3\% vs. 51.7\%, p<0.001) (Table

$321 \quad 2$, Fig.5);

322 v) no change for the use of recreational drugs (44.6\% in DBP $v s$.

$32355.4 \%$ in OLE, $\mathrm{p}=0.3$ ), but a significant decrease for alcohol

324 consumption (51.6\% in DBP vs. $48.4 \%$ in OLE, $\mathrm{p}<0.001$ ) (Table

325 2, Fig.6). 
326 It is important to underline that all the descriptive statistics listed

327 in (i) to (v) above are based on comparisons of averages between

328 DBP and OLE, and none suggested a trend.

329 Multivariate analysis of sexual behaviors and prevention

$330 \quad$ strategies

331 The GEE model estimates (Table 3a) showed a significant

332 decrease both in the number of sexual partners and in the number

333 of sexual relations between the DBP and OLE study phases. On

334 average, participants in the OLE had 0.37 fewer sexual partners

335 during the previous 2 months than those in the DBP (Coefficient

336 [CI95\%], p-value; $-0.37[-0.70--0.04], \mathrm{p}=0.03)$ and 0.25 fewer

337 sexual relations during the previous 4 weeks $(-0.25[-0.49-$

$3380.00], 0.04)$.

339 With regard to the type of partner, the GEE model estimates

340 (Table 3b) showed that the proportion of sexual relations with an

341 unknown casual partner was significantly lower (on average

342 25\%) during OLE than DBP (Odds Ratio [CI95\%], p-value:

$3430.75[0.62-0.92], 0.005)$. As the GEE model accounted for time

344 trends, we were able to estimate that, all things being equal, the

345 proportion of sexual relations with unknown casual partners

346 decreased between the DBP and OLE.

347 With respect to prevention strategies, the GEE model estimates

348 (Table $3 \mathrm{~b}$ ) confirmed that the proportion of CAS during the most

349 recent sexual relation increased significantly (on average 32\%

350 per year), but only during the OLE (1.32[1.04-1.67], 0.02, Table 
$3513 b$ ). The proportion of 'suboptimal PrEP use' (Table 3b) during

352 the most recent sexual relation, decreased over time during the

353 whole follow-up (i.e., the DBP and OLE combined as one long

354 period $)(0.75[0.58-0.97], \mathrm{p}=0.03$, Table $3 \mathrm{~b})$. Figure 4 shows that

355 the proportion of suboptimal PrEP use decreased from $33.5 \%$ to

$35614.3 \%$ during the whole follow-up. Again, the fact that the GEE

357 model took into account time trends resulted in a significant

358 decrease of $25 \%$ per year being highlighted, something which

359 the Chi-square test was not able to observe.

360 With regard to combined prevention, the GEE model (Table 3b)

361 showed, all things being equal, a significant decrease in 'PrEP

362 use only' (on average $27 \%$ per year) $(0.73[0.55-0.96], 0.03)$ and

363 in 'PrEP and condom use' (on average 30\% per year)

$364(0.70[0.51-0.95], 0.02)$. As for the use of recreational drugs

365 (Table 3b), no changes were observed in the GEE models

366 concerning, but estimates did show a significant decrease in

367 alcohol consumption between the DBP and OLE phases

$368 \quad(0.74[0.61-0.90], 0.002)$.

369 From these results we see that our decision to account for intra-

370 individual correlations of repeated measures over time with GEE

371 models offered a better overview of sexual behavior changes

372 than just describing the dataset.

\section{Discussion}

374 Our analysis provided estimates for the changes in sexual

375 behaviors after PrEP initiation in the ANRS-IPERGAY trial in 
high-risk HIV-negative MSM taking on-demand PrEP.

377 Results from GEE models showed in increase in several

378 protective behaviors regarding HIV risk between DBP and OLE,

379 including a significant decrease in the number of sexual relations

380 and sexual partners, a decrease in the proportion of sexual

381 relations with unknown causal partners, and a decrease in

382 alcohol consumption during sexual relations. However, results

383 also showed an increase in risky sexual behaviors, including a

384 significant increase in CAS in the OLE phase. The increase in

385 CAS is of major concern in terms of IST incidence.

386 Non-longitudinal results showed a high level of 'correct' and

387 'suboptimal' PrEP use during DBP and OLE, which is consistent

388 with findings from a previous study on the same cohort (22). An

389 increase in the proportions of sexual encounters where PrEP-

390 only and combined PrEP-condom prevention was used was also

391 observed between the DBP and OLE. However, GEE results

392 provided a more precise measure of the evolution of PrEP use in

393 the trial. Indeed, the proportions of suboptimal PrEP, PrEP-only

394 and combined PrEP-condom prevention all decreased

395 significantly over time, not only after the placebo arm was

396 suppressed. These results were not seen by the non-longitudinal

397 analysis, which focused only on changes between the DBP and

398 OLE (i.e., it did not take trends over time into account). Results

399 from our GEE models might reflect the issue of lack of PrEP

400 persistence which has been highlighted elsewhere $(26,27)$. A 
401 recent qualitative study showed that the barriers to PrEP

402 persistence are strongly linked to issues regarding insurance

403 costs and to scheduled medical appointments which are

404 mandatory in PrEP programs (28). In our study, PrEP was free

405 of charge for participants. Accordingly, the trial's scheduled

406 two-monthly medical appointments may have led to a lack of

407 PrEP persistence (i.e., temporary treatment interruptions).

408 PrEP use did not seem to impact recreational drug use in the

409 sexual context or the proportion of sexual relations with multiple

410 partners or with known casual partners.

411 Our study took into account a larger set of sexual behavioral

412 factors than in the majority of previous studies. Accordingly, our

413 results may provide more detailed information on the impact of

414 PrEP use on sexual behaviors and prevention strategy dynamics

415 in MSM.

416 The increase in CAS during the OLE is a major concern for the

417 risk of STI infection. However, while previous results from the

418 ANRS-IPERGAY trial showed that the rate of STI was high

419 among participants, it did not differ between the DBP and OLE

420 study phases (22). Different studies have shown similar results

421 (i.e., increase in CAS without an increase in STI among MSM

422 PrEP users) (2) (29). This suggests that PrEP uptake is not the

423 only predictive factor of STI. While a study in Germany showed

424 that PrEP uptake did not lead to an increase in of STI (30), a

425 recent retrospective cohort study of PrEP users in Canada found 
426 the opposite at 12 months after PrEP initiation (31).

427 Therefore, the relationship between PrEP uptake, CAS and

428 increase in STI is not clear. In any case, STI do not undermine

429 PrEP efficacy and if anything, PrEP monitoring is an opportunity

430 to increase testing and treatment for STI (22).

431 With regard to risk compensation (RC), our results highlighted

432 changes in behavior after PrEP initiation which reflected greater

433 protection but also greater risk. More specifically, the number

434 of sexual relations and number of sexual partners both

435 decreased, as did sexual relations with unknown casual partners

436 and alcohol consumption during sex. Risky behaviors included

437 an increase in CAS - despite the STI rate remaining stable

438 between the DBP and OLE (20) - and issues associated with

439 PrEP persistence over time. Therefore, our results were unable

440 to conclude whether a risk compensation mechanism was

441 present or not with on-demand PrEP in the ANRS-IPERGAY

442 trial.

443 However, a recent publication suggested that $\mathrm{RC}$ is not a valid

444 framework to study PrEP use (7). Some studies, including a

445 qualitative study previously conducted among participants

446 during the OLE phase of the ANRS-IPERGAY trial, have

447 highlighted that PrEP has the potential to reduce fear of HIV

448 infection and can lead to a more satisfying sex life $(32,33,34)$. In

449 that ANRS-IPERGAY study, participants perceived condoms as

450 a barrier (materially and symbolically) to pleasure and desire, 
451 whereas PrEP was seen as a means to freely choose sexual

452 positions and to better enjoy intimacy (34). Participants also

453 reported improved sexual quality of life thanks to PrEP use (34).

454 These results reflect the World Health Organization's policy that

455 everyone has the right to a good quality of sexual life (35).

456 Therefore, one of the most important benefits of PrEP use is an

457 improvement in sexual life, something which not considered in

458 the RC concept (7).

459 Moreover, the concept of RC was originally established for the

460 road injury prevention context, and subsequently applied to that

461 of sexual behaviors (36) without considering that psychosocial

462 factors may differ between contexts.

463 Therefore, sexual behavior changes linked to PrEP initiation

464 should not be studied only in light of RC but also in terms of

465 quality of sexual life and sexual health.

466 Our results showed that HIV risk taking in MSM depends on the

467 prevention tools available to them. The MSM recruited in

468 ANRS-IPERGAY were recruited on the basis of their high-risk

469 practices. After PrEP initiation, this risk was largely removed

470 with only one HIV infection occurring during the OLE (22). In

471 addition, a previous study on "chemsexers" in the ANRS-

472 IPERGAY trial showed that they were more likely to report

473 high-risk sexual practices but also had a higher perception of risk

474 (37). Chemsexers were also more likely to use PrEP correctly

475 (37). These results would therefore suggest that PrEP may also 
476 be a suitable tool to reduce HIV transmission in high-risk

477 populations, such as chemsexers.

478 Our results provide recommendations which should be taken

479 into account for future PrEP cohort studies. The increase in CAS

480 in ANRS-IPERGAY and the resulting potential increase of STI

481 are serious public health concerns for MSM PrEP users. In order

482 to reduce them, it may be useful to increase the focus on STI

483 prevention during PrEP counseling and move to a global sexual

484 health support. Establishing protocols for partner notification

485 may also accelerate treatment for STI in MSM, in turn reducing

486 the potential STI rate in this population. Furthermore, PrEP

487 persistence is a major issue in PrEP success. PrEP adherence

488 slowly decreased over time in our trial. It would be useful in

489 future studies on other cohorts to provide qualitative data

490 concerning PrEP persistence and its associated factors in order

491 to adapt PrEP protocols. Access to PrEP needs to be investigated

492 in greater detail, especially regarding the issue of mandatory

493 medical appointments and more globally, the various steps

494 which to be followed in order to obtain it.

495 Our study has limitations. First, the data we analyzed were

496 collected in a clinical trial with a strict follow-up and with highly

497 motivated participants. Therefore, our results cannot be

498 generalized to all PrEP users. Second, we do not have specific

499 qualitative data for all the elements investigated in our study,

500 which could have helped us to understand the reasons for the 
501 different prevention choices, specifically for sexual relations

502 without PrEP or condoms (i.e., an individual choice, unavailable

503 PrEP at the time and location of sexual relations, etc.). Third, the

504 participant-peer counsellor relationship may have led to social

505 desirability bias. Fourth, we had no control group with the same

506 characteristics as our participants to compare changes in sexual

507 behaviors, and to confirm that the changes observed were indeed

508 related to participation in the PrEP trial and not due to trends in

509 sexual practices in the MSM community.

\section{Conclusion}

511 The move from the DBP to the OLE study in high-risk HIV-

512 negative MSM enrolled in the ANRS-IPERGAY trial was

513 associated with several protective changes in sexual behaviors.

514 Reductions in the numbers of sexual partners and number of

515 sexual relations were observed, as were reductions in sexual

516 relations with unknown casual partners and alcohol consumption

517 during sex. However, an increase in condomless sex was also

518 observed, which highlights the increased potential risk of STI

519 associated with PrEP use.

520 Further in-depth studies need to explore the characteristics

521 associated with condomless anal sex without PrEP, the

522 introduction of PrEP in real-world contexts and the PrEP

523 persistence dynamic. 


\section{References}

1. Grant RM, Lama JR, Anderson PL, McMahan V, Liu AY, Vargas L, et al. Preexposure Chemoprophylaxis for HIV Prevention in Men Who Have Sex with Men. N Engl J Med. 2010 Dec 30;363(27):2587-99.

2. McCormack S, Dunn DT, Desai M, Dolling DI, Gafos M, Gilson R, et al. Pre-exposure prophylaxis to prevent the acquisition of HIV-1 infection (PROUD): effectiveness results from the pilot phase of a pragmatic open-label randomised trial. The Lancet. 2016 Jan;387(10013):53-60.

3. Molina J-M, Capitant C, Spire B, Pialoux G, Cotte L, Charreau I, et al. On-Demand Preexposure Prophylaxis in Men at High Risk for HIV-1 Infection. N Engl J Med. 2015 Dec 3;373(23):2237-46.

4. Eaton LA, Kalichman S. Risk compensation in HIV prevention: implications for vaccines, microbicides, and other biomedical HIV prevention technologies. Curr HIV/AIDS Rep. 2007 Dec;4(4):165-72.

5. Hogben M, Liddon N. Disinhibition and risk compensation: scope, definitions, and perspective. Sex Transm Dis. 2008 Dec;35(12):1009-10.

6. Collin J, David P-M, editors. Vers une pharmaceuticalisation de la société? le médicament comme objet social. Québec (Québec): Presses de l'Université du Québec; 2016. 272 p. (Problèmes sociaux et interventions sociales).

7. Rojas Castro D, Delabre RM, Molina J. Give PrEP a chance: moving on from the "risk compensation" concept. J Int AIDS Soc [Internet]. 2019 Aug [cited 2019 Oct 31];22(S6). Available from: https://onlinelibrary.wiley.com/doi/abs/10.1002/jia2.25351

8. Golub SaritA, Gamarel KE, Surace A. Demographic Differences in PrEP-Related Stereotypes: Implications for Implementation. AIDS Behav. 2017 May;21(5):1229-35.

9. Girard G. "La pilule qui change tout?” analyse des débats québécois autour de la prophylaxie préexposition du VIH. In: Vers une pharmaceuticalisation de la société. Québec: Presses de l’Université du Québec; 2016. p. 193-218.

10. Kalampalikis N, Apostolidis T. La perspective socio-génétique des représentations sociales. In: Les représentations sociales. De Boeck. Bruxelles: De Boeck; 2016. p. 6985. (Ouvertures Psychologiques).

11. Jansen M, Tromp N, Baltussen R. PrEP: why we are waiting. Lancet HIV. Lancet HIV. 2016; e11-12.

12. Otis J, Lévy JJ-, Bernier M, editors. La recherche communautaire VIH/sida: des savoirs engagés. Québec (Québec): Presses de 1'Université du Québec; 2015. 366 p. (Collection Santé et société).

13. Glasgow RE, Eckstein ET, ElZarrad MK. Implementation Science Perspectives and Opportunities for HIV/AIDS Research: Integrating Science, Practice, and Policy. JAIDS J Acquir Immune Defic Syndr. 2013 Jun;63:S26-31. 
14. Morin M, Apostolidis T. Contexte social et santé. In: Traité de psychologie de la santé. Dunod. Paris: Gustave-Nicolas Fisher; 2002.

15. Liu AY, Vittinghoff E, Chillag K, Mayer K, Thompson M, Grohskopf L, et al. Sexual Risk Behavior Among HIV-Uninfected Men Who Have Sex With Men Participating in a Tenofovir Preexposure Prophylaxis Randomized Trial in the United States: JAIDS J Acquir Immune Defic Syndr. 2013 Sep;64(1):87-94.

16. Sagaon-Teyssier L, Suzan-Monti M, Demoulin B, Capitant C, Lorente N, Préau M, et al. Uptake of PrEP and condom and sexual risk behavior among MSM during the ANRS IPERGAY trial. AIDS Care. 2016 Mar 24;28(sup1):48-55.

17. Marcus JL, Glidden DV, Mayer KH, Liu AY, Buchbinder SP, Amico KR, et al. No Evidence of Sexual Risk Compensation in the iPrEx Trial of Daily Oral HIV Preexposure Prophylaxis. Stephenson R, editor. PLoS ONE. 2013 Dec 18;8(12):e81997.

18. Grant RM, Anderson PL, McMahan V, Liu A, Amico KR, Mehrotra M, et al. Uptake of pre-exposure prophylaxis, sexual practices, and HIV incidence in men and transgender women who have sex with men: a cohort study. Lancet Infect Dis. 2014 Sep;14(9):8209 .

19. Liu AY, Cohen SE, Vittinghoff E, Anderson PL, Doblecki-Lewis S, Bacon O, et al. Preexposure Prophylaxis for HIV Infection Integrated With Municipal- and CommunityBased Sexual Health Services. JAMA Intern Med. 2016;176(1):75.

20. Oldenburg CE, Nunn AS, Montgomery M, Almonte A, Mena L, Patel RR, et al. Behavioral Changes Following Uptake of HIV Pre-exposure Prophylaxis Among Men Who Have Sex with Men in a Clinical Setting. AIDS Behav. 2018 Apr;22(4):1075-9.

21. Volk JE, Marcus JL, Phengrasamy T, Blechinger D, Nguyen DP, Follansbee S, et al. No New HIV Infections With Increasing Use of HIV Preexposure Prophylaxis in a Clinical Practice Setting: Figure 1. Clin Infect Dis. 2015 Nov 15;61(10):1601-3.

22. Molina J-M, Charreau I, Spire B, Cotte L, Chas J, Capitant C, et al. Efficacy, safety, and effect on sexual behaviour of on-demand pre-exposure prophylaxis for HIV in men who have sex with men: an observational cohort study. Lancet HIV. 2017 Sep;4(9):e402-10.

23. For the iPrEx Study Team, Amico KR, Mehrotra M, Avelino-Silva VI, McMahan V, Veloso VG, et al. Self-reported Recent PrEP Dosing and Drug Detection in an Open Label PrEP Study. AIDS Behav. 2016 Jul;20(7):1535-40.

24. Zeger SL, Liang K-Y, Albert PS. Models for Longitudinal Data: A Generalized Estimating Equation Approach. Biometrics. 1988 Dec;44(4):1049.

25. Zeger SL, Liang K-Y. Longitudinal Data Analysis for Discrete and Continuous Outcomes. Biometrics. 1986 Mar;42(1):121.

26. Spinelli MA, Buchbinder SP. Pre-exposure Prophylaxis Persistence Is a Critical Issue in PrEP Implementation. Clin Infect Dis. 2019 Sep 12; ciz896. 
27. Rolle C-P, Onwubiko U, Jo J, Sheth AN, Kelley CF, Holland DP. PrEP Implementation and Persistence in a County Health Department Setting in Atlanta, GA. AIDS Behav. 2019 Oct;23(S3):296-303.

28. D'Angelo AB, Lopez-Rios J, Flynn AWP, Holloway IW, Pantalone DW, Grov C. Insurance- and medical provider-related barriers and facilitators to staying on PrEP: results from a qualitative study. Transl Behav Med. 2020 Feb 17;ibz191.

29. Morgan E, Dyar C, Newcomb M, D’Aquila R, Mustanski B. PrEP use and sexually transmitted infections are not associated longitudinally in a cohort study of young men who have sex with men in Chicago [Internet]. IAS; 2019 Jul [cited 2019 Oct 30]; Mexico. Available from: http://programme.ias2019.org/Abstract/Abstract/4417

30. Streeck H, Janssen K, Crowell TA, Jessen H, Cordes C, Scholten S, et al. Prospective, multicenter study to assess point prevalence, incidence and recurrence of sexually transmitted infections in men who have sex with men in Germany: BRAHMS study [Internet]. IAS; 2019 Jul [cited 2019 Oct 30]; Mexico. Available from: http://programme.ias2019.org/Abstract/Abstract/1906

31. Nguyen V-K, Greenwald ZR, Trottier H, Cadieux M, Goyette A, Beauchemin M, et al. Incidence of sexually transmitted infections before and after Pre-Exposure Prophylaxis for HIV: a cohort study. AIDS. 2017 Dec;1.

32. Koester K, Amico RK, Gilmore H, Liu A, McMahan V, Mayer K, et al. Risk, safety and sex among male PrEP users: time for a new understanding. Cult Health Sex. 2017 Dec 2;19(12):1301-13.

33. Auerbach JD, A Hoppe T. Beyond "getting drugs into bodies": social science perspectives on pre-exposure prophylaxis for HIV. J Int AIDS Soc [Internet]. $2015 \mathrm{Jul}$ 20 [cited 2019 Oct 31];18(4 (Suppl 3)). Available from: http://doi.wiley.com/10.7448/IAS.18.4.19983

34. Mabire X, Puppo C, Morel S, Mora M, Rojas Castro D, Chas J, et al. Pleasure and PrEP: Pleasure-Seeking Plays a Role in Prevention and in Sexual Quality of Life, and Could Lead to PrEP Initiation. Am J Men's Health. 2019; In Press:1-14.

35. World Health Organization. PREVENTION AND TREATMENT OF HIV AND OTHER SEXUALLY TRANSMITTED INFECTIONS AMONG MEN WHO HAVE SEX WITH MEN AND TRANSGENDER PEOPLE Recommendations for a public health approach. Genève: World Health Organization; 2011 p. 1-88.

36. Richens J, Imrie J, Copas A. Condoms and seat belts: the parallels and the lessons. The Lancet. 2000 Jan;355(9201):400-3.

37. Roux P, Fressard L, Suzan-Monti M, Chas J, Sagaon-Teyssier L, Capitant C, et al. Is ondemand HIV pre-exposure prophylaxis a suitable tool for men who have sex with men who practice chemsex? Results from a sub-study of the ANRS-IPERGAY trial: JAIDS J Acquir Immune Defic Syndr. 2018 Jun;1. 


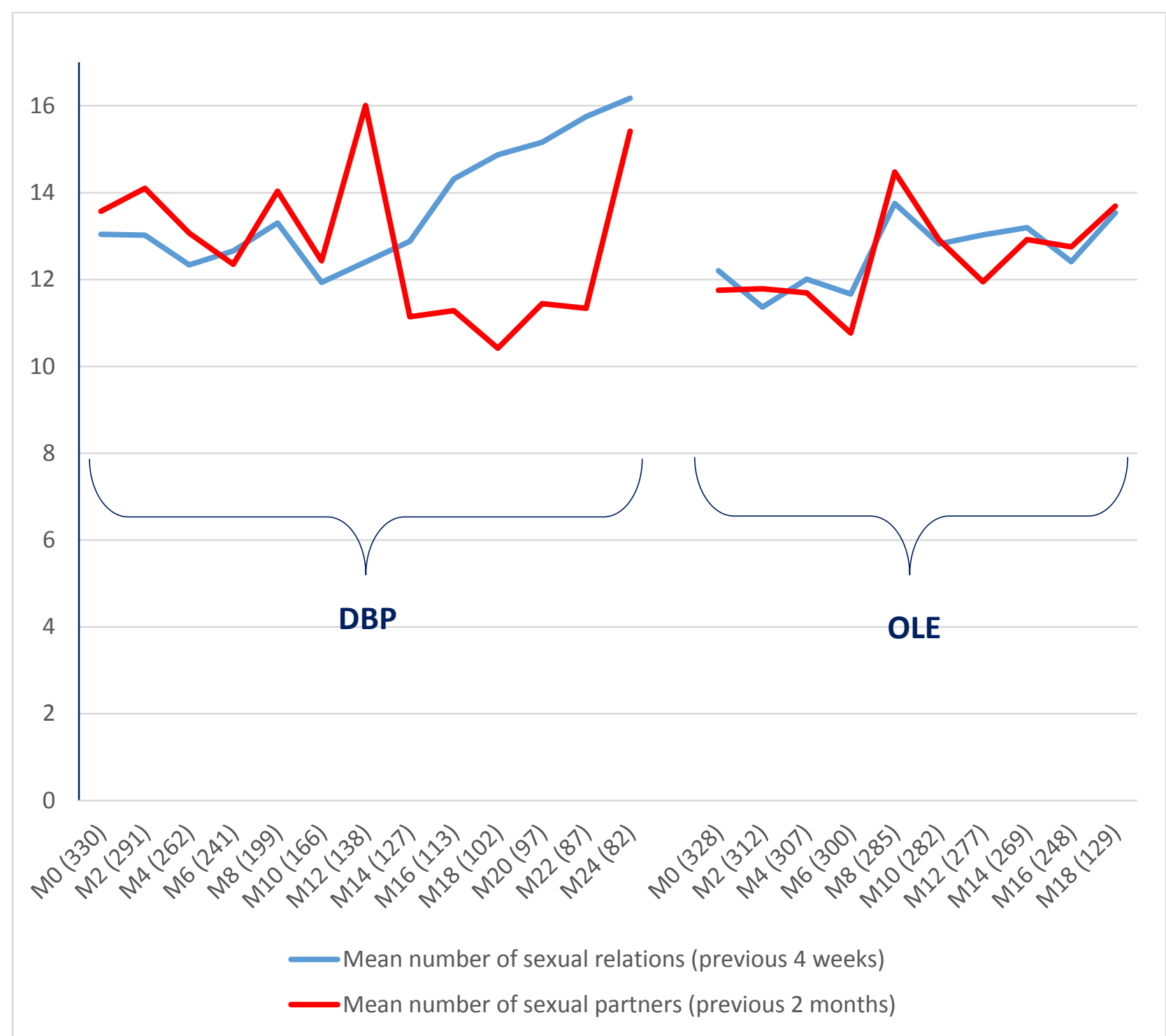

Fig.1 Evolution of the mean number of sexual relations and number of partners $(n=332)$ 


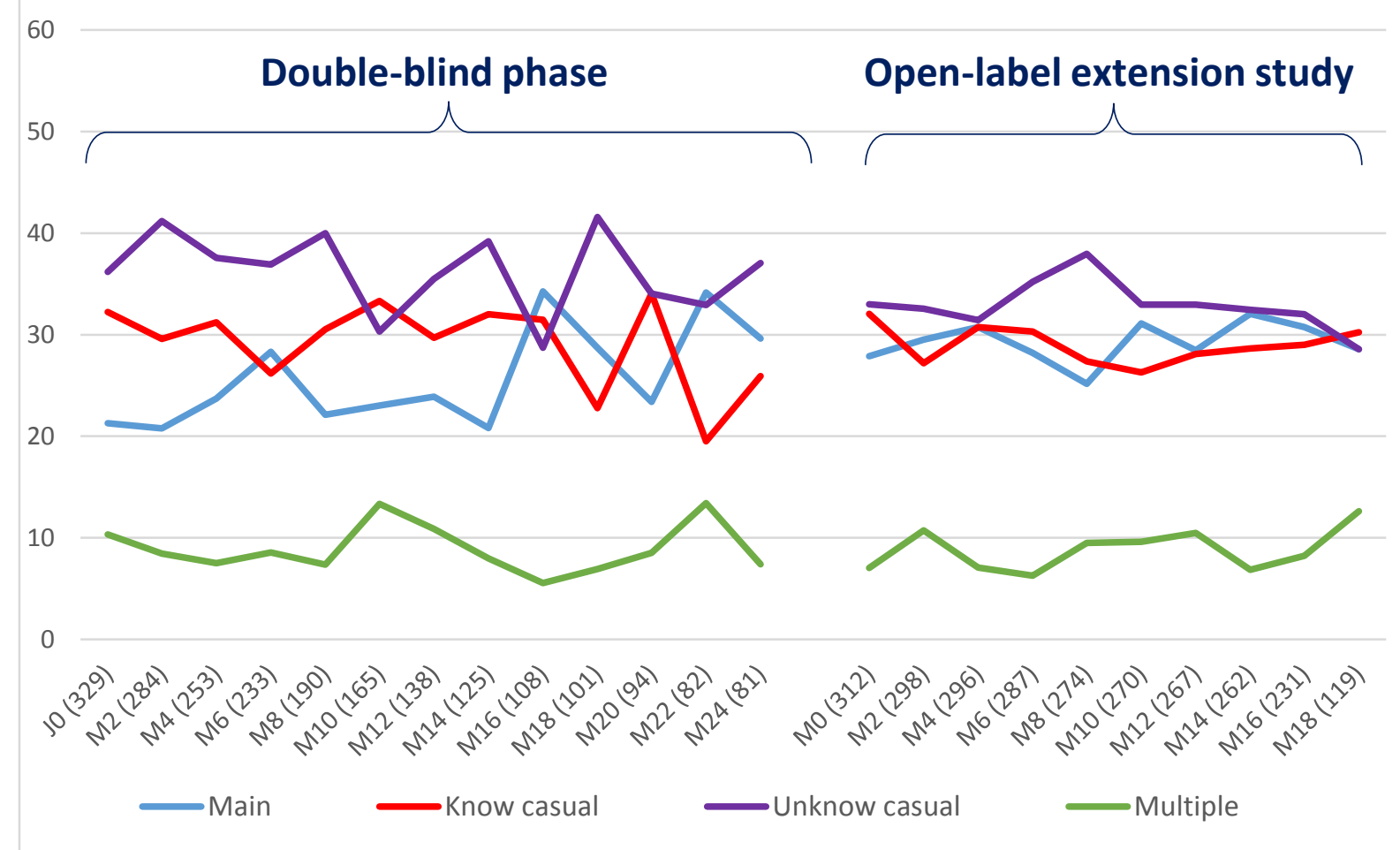

Fig.2 Evolution of the type of partner at most recent sexual encounter $(n=332)$ 


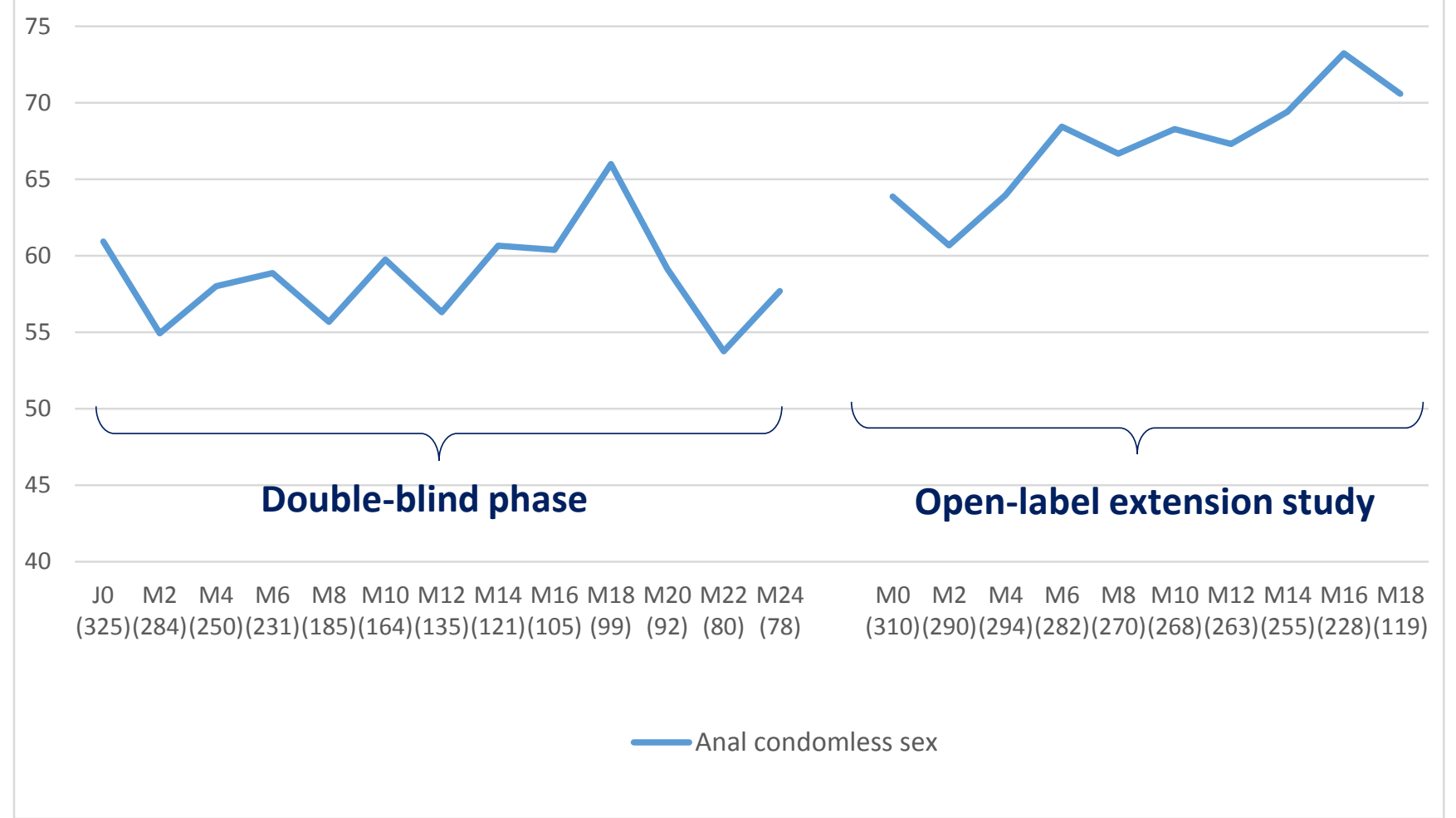

Fig.3 Evolution of anal condomless sex $(n=332)$ 

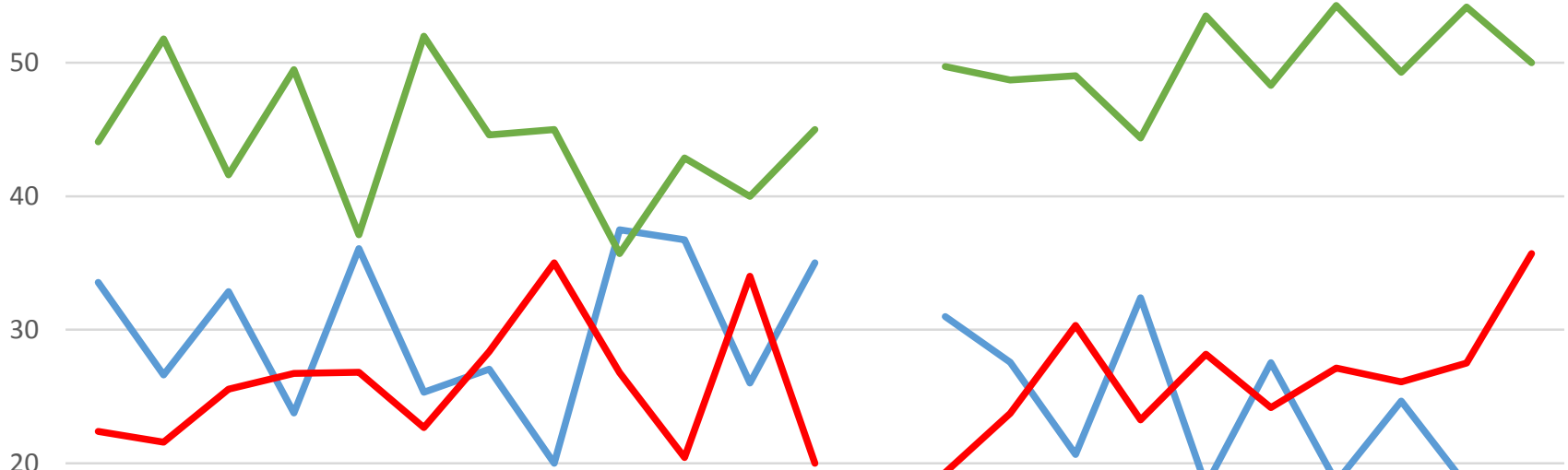

10

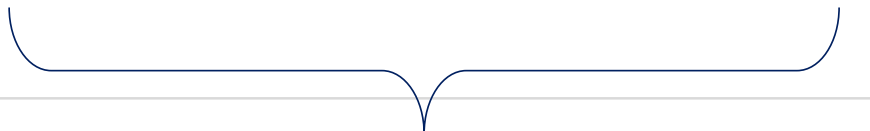

Double-blind phase

\section{Open-label extension study}

0

M2 M4 M6 M8 M10 M12 M14 M16 M18 M20 M22 M24

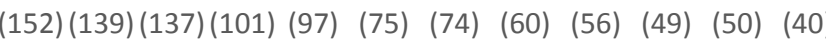

M0 M2 M4 M6 M8 M10 M12 M14 M16 M18

(171) (156) (155) (142) (142) (149) (140) (138) (120) (70)

Suboptimal adherence

No PrEP

Correct adherence

Fig.4 Evolution of PrEP adherence $(n=332)$ 
80 70 Double-blind phase Open-label extension study

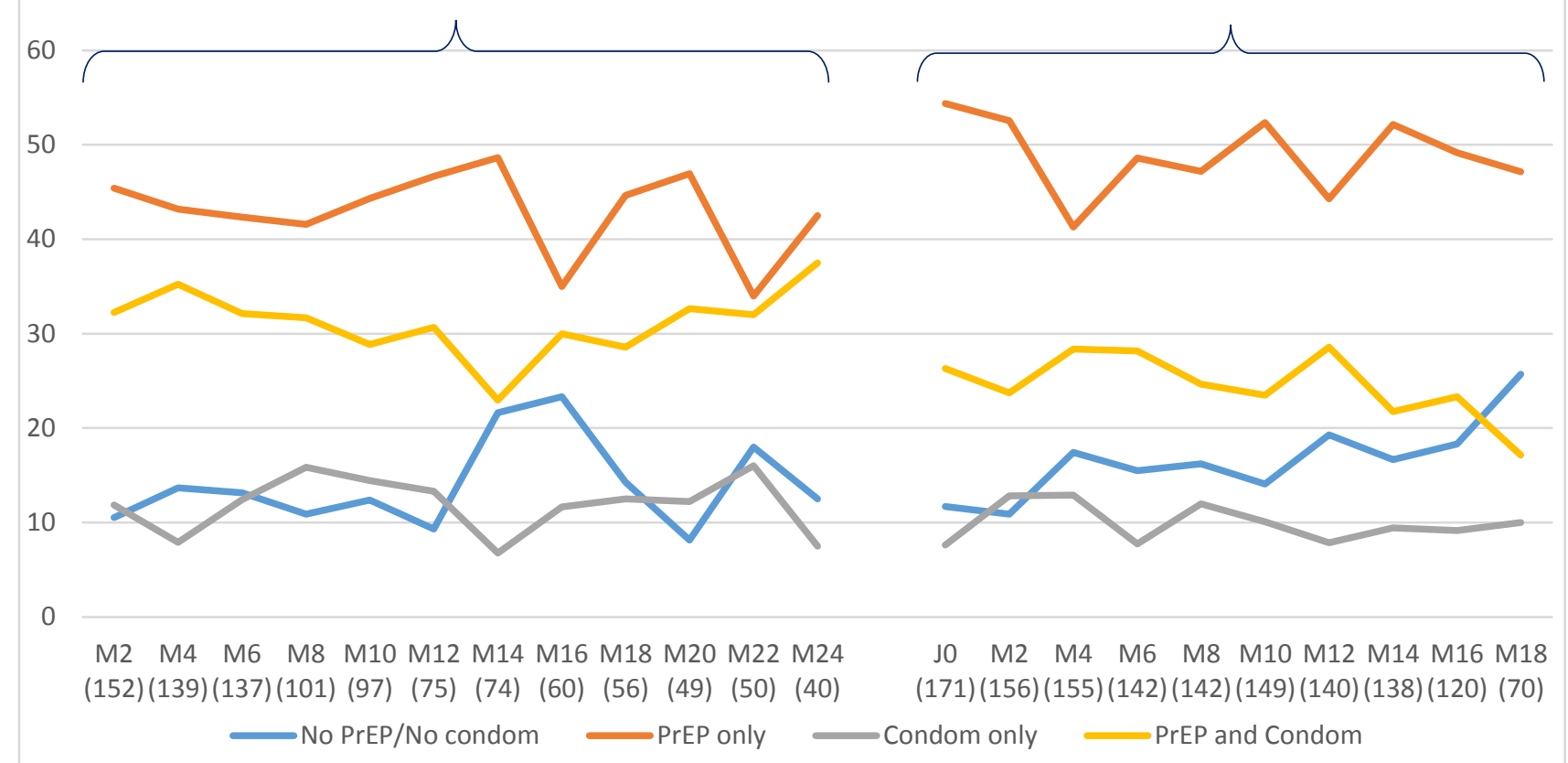

Fig.5 Evolution of combined prevention $(n=332)$ 


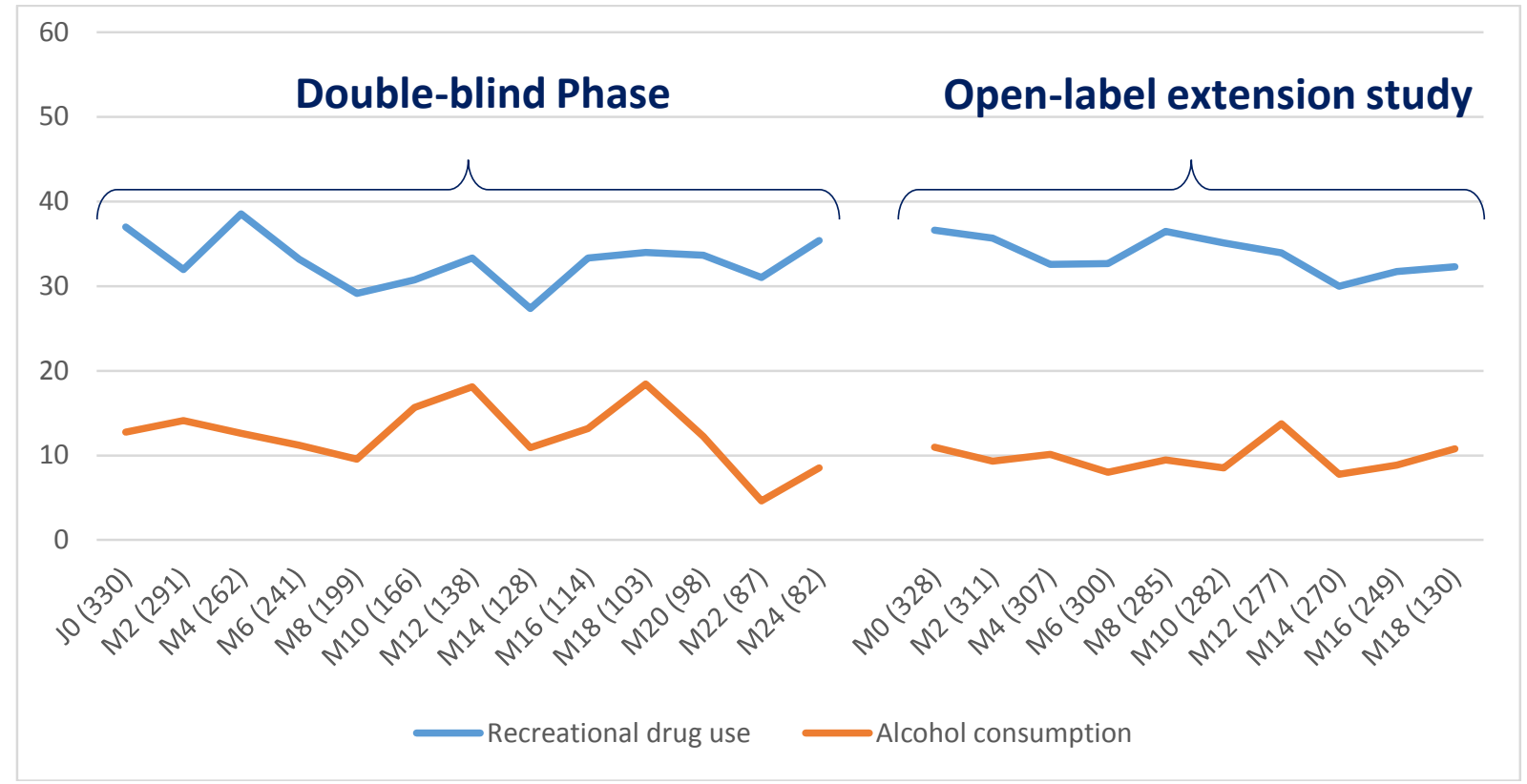

Fig.6 Evolution of recreational drug and alcohol use $(n=332)$ 
Table 1 Main Characteristics at DBP baseline of those who participated in both the DBP and OLE phases (ANRS IPERGAY, n=332)

\begin{tabular}{|c|c|}
\hline & $\begin{array}{c}\text { Number of those who } \\
\text { participated in both phases } \\
(\mathrm{N}=332)\end{array}$ \\
\hline Age, mean (Standard Deviation, SD) & $35.8(14.0)$ \\
\hline \multicolumn{2}{|l|}{ Sexual orientation, $\mathrm{n}(\%)$} \\
\hline Gay & $305(96.5)^{\mathrm{a}}$ \\
\hline Bisexual & $10(3.2)$ \\
\hline Trans / transsexual / transgender & $1(0,3)$ \\
\hline \multicolumn{2}{|l|}{ Education level, n (\%) } \\
\hline$<$ High-school diploma & $86(26.1)^{b}$ \\
\hline$\geq$ High-school diploma & $243(73.9)$ \\
\hline \multicolumn{2}{|l|}{ Active employment, $\mathrm{n}(\%)$} \\
\hline No & $51(15.4)^{\mathrm{c}}$ \\
\hline Yes & $279(84.6)$ \\
\hline \multicolumn{2}{|l|}{ Main male partner, n (\%) } \\
\hline No & $191(58.1)^{\mathrm{b}}$ \\
\hline Yes & $138(41.9)$ \\
\hline \multicolumn{2}{|l|}{ Main male partner HIV status, n (\%) } \\
\hline HIV negative & $84(61.3)^{\mathrm{d}}$ \\
\hline HIV positive & $43(31.4)$ \\
\hline Do not know & $10(7.3)$ \\
\hline $\begin{array}{l}\text { Number of sexual relations (previous } 4 \text { weeks), mean } \\
\text { (SD) }\end{array}$ & $13(11.7)^{\mathrm{e}}$ \\
\hline $\begin{array}{l}\text { Number of sexual partners (previous } 2 \text { months), mean } \\
\text { (SD) }\end{array}$ & $13.5(16.1)$ \\
\hline \multicolumn{2}{|l|}{$\begin{array}{l}\text { Condomless anal sex during most recent sexual } \\
\text { relation, } \mathrm{n}(\%)\end{array}$} \\
\hline No & $128(39.3)^{\mathrm{e}}$ \\
\hline Yes & $198(60.7)$ \\
\hline \multicolumn{2}{|l|}{$\begin{array}{l}\text { PrEP adherence (M2) during most recent sexual } \\
\text { relation, } \mathrm{n}(\%)\end{array}$} \\
\hline No PrEP & $34(22.2)^{f}$ \\
\hline Suboptimal & $51(33.3)$ \\
\hline Correct & $67(44.5)$ \\
\hline \multicolumn{2}{|l|}{$\begin{array}{l}\text { Type of partner during most recent sexual relation, } \mathrm{n} \\
(\%)\end{array}$} \\
\hline Multiple partners & $34(10.3)^{\mathrm{c}}$ \\
\hline Unknown casual partner & $119(36.0)$ \\
\hline Known casual partner & 107 (32.6) \\
\hline Main partner & $70(21.2)$ \\
\hline
\end{tabular}


Number of those who

participated in both phases

$(\mathrm{N}=332)$

Recreational drug use during most recent sexual relation, $\mathrm{n}(\%)$

No

$210(63.3)$

Yes

$122(36.7)$

Alcohol consumption during most recent sexual relation, $\mathrm{n}(\%)$

No

Yes

\footnotetext{
16 missing values

b 3 missing values

c 2 missing values

d195 missing values

e 6 missing values

f 180 missing values
} 
Table 2 Comparison of sexual behaviors and prevention strategy variables between the DBP and OLE phases ( $\mathrm{n}=332 ; 4978$ questionnaires)

$$
\begin{array}{ccc}
\text { DBP } & \text { OLE } & \text { p-value } \\
(n=2239,45.0 \%) & (n=2739,55.0 \%) &
\end{array}
$$

Number of sexual relations (previous 4

weeks), mean (Standard Deviation, SD)

Number of sexual partners (previous 2

months), mean (SD)

Condomless anal sex at most recent sexual relation, $\mathrm{n}(\%)$

$$
\begin{aligned}
& \text { Yes } \\
& \text { No }
\end{aligned}
$$

PrEP adherence at most recent sexual relation, $\mathrm{n}(\%)$

$$
\begin{aligned}
& \text { No PrEP } \\
& \text { Suboptimal } \\
& \text { Correct }
\end{aligned}
$$

PrEP-condom use at most recent sexual relation, $\mathrm{n}(\%)$

$$
\begin{aligned}
& \text { No PrEP - No condom } \\
& \text { PrEP only } \\
& \text { Condom only } \\
& \text { PrEP and condom }
\end{aligned}
$$

Type of partner at most recent sexual relation, $\mathrm{n}(\%)$

\section{Multiple partners}

Unknown casual partner

Known casual partner

Main partner

Recreational drug use at most recent sexual relation, $\mathrm{n}(\%)$

$$
\begin{aligned}
& \text { Yes } \\
& \text { No }
\end{aligned}
$$

Alcohol consumption at most recent sexual relation, $\mathrm{n}(\%)$

$$
\begin{aligned}
& \text { Yes } \\
& \text { No } \\
& \text { a Chi-Square Test/ T-Test } \\
& \text { b75 missing data } \\
& \text { c } 128 \text { missing data } \\
& \text { d } 16 \text { missing data } \\
& \text { e } 19 \text { missing data } \\
& \text { f } 86 \text { missing data } \\
& \text { g } 160 \text { missing data } \\
& \text { h } 1209 \text { missing data }
\end{aligned}
$$

$\begin{array}{cc}225(53.4)^{\mathrm{k}} & 0.32 \\ 869(52.0) & <0.005 \\ 760(53.9) & 0.28 \\ 766(58.9) & <0.001\end{array}$

$928(55.4)$

0.36

$1811(54.9) \quad 0.36$ 
Table 3a Evolution of sexual behaviors between the DBP and OLE phases (GEE, continuous variables)

\begin{tabular}{ccc}
\hline & $\begin{array}{c}\text { Evolution in the number of } \\
\text { sexual relation (previous 4 } \\
\text { weeks) }\end{array}$ & $\begin{array}{c}\text { Evolution of the number of sexual } \\
\text { partners (previous 2 months) }^{\mathbf{2}}\end{array}$ \\
\hline & Coefficient [CI95\%], p-value* & Coefficient [CI95\%], p-value* \\
\hline Phase: DBP (ref) vs OLE & $-0.25[-0.49-0.00], 0.04$ & $-0.37[-0.70--0.04], 0.03$ \\
Evolution over time & $0.09[0.00-0.18], 0.05$ & $-0.07[-0.19-0.06], 0.30$ \\
Evolution over time X phase(OLE) & - & $0.16[0.00-0.33], 0.05$ \\
QIC** & -136995.0515 & -133604.7802 \\
\hline
\end{tabular}

* Results from the GEE model

** Quasi-likelihood under the Independence model Criterion

${ }^{1}$ QIC model with study phases as explicative variables: -134142.4725; model with time, study phases and the interaction of time with study phases as explicative variables: -136975.3351

2 QIC model with study phases as explicative variables: -133100.2591; model with time and study phases as explicative variables: -133076.6388 
Table 3b Evolution of sexual behaviors and prevention strategies between the DBP and OLE phases (GEE, categorical variables)

\begin{tabular}{|c|c|c|c|c|c|c|}
\hline & $\begin{array}{c}\text { Condomless sex } \\
(\text { ref No })^{1}\end{array}$ & \multicolumn{2}{|c|}{ PrEP adherence (ref No PrEP) $)^{2}$} & \multicolumn{3}{|c|}{ Combined PrEP-condom use (ref. No PrEP or condom use) ${ }^{3}$} \\
\hline & $\begin{array}{c}\text { Yes } * \\
\text { OddsRatio } \\
{[\mathrm{CI} 95 \%], \mathrm{p} \text {-value }} \\
\end{array}$ & $\begin{array}{c}\text { Suboptimal* } \\
\text { OddsRatio } \\
\text { [CI95\%], p-value } \\
\end{array}$ & $\begin{array}{c}\text { Correct* } \\
\text { OddsRatio } \\
\text { [CI95\%], p-value } \\
\end{array}$ & $\begin{array}{l}\text { Condom only* } \\
\text { OddsRatio } \\
\text { [CI95\%], p-value }\end{array}$ & $\begin{array}{c}\text { PrEP only* } \\
\text { OddsRatio } \\
\text { [CI95\%], p-value } \\
\end{array}$ & $\begin{array}{c}\text { PrEP and condom* } \\
\text { OddsRatio [CI95\%], } \\
\text { p-value }\end{array}$ \\
\hline $\begin{array}{c}\text { Phase: } \\
\text { DBP (ref) vs } \\
\text { OLE }\end{array}$ & $\begin{array}{c}0.63[0.38-1.03] \\
0.06\end{array}$ & $\begin{array}{c}1.41[0.76-2.62] \\
0.27\end{array}$ & $\begin{array}{c}1.50[0.90-2.52] \\
0.12\end{array}$ & $\begin{array}{c}1.30[0.63-2.70], \\
0.48\end{array}$ & $\begin{array}{c}1.80[0.98-3.32], \\
0.05\end{array}$ & $\begin{array}{c}1.39[0.70-2.77] \\
0.34\end{array}$ \\
\hline $\begin{array}{l}\text { Evolution over } \\
\text { time }\end{array}$ & $\begin{array}{c}1.02[0.86-1.22] \\
0.82\end{array}$ & $\begin{array}{c}0.75[0.58-0.97] \\
0.03\end{array}$ & $\begin{array}{c}0.85[0.69-1.06] \\
0.15\end{array}$ & $\begin{array}{c}0.74[0.52-1.05] \\
0.09\end{array}$ & $\begin{array}{c}0.73[0.55-0.96], \\
0.03\end{array}$ & $\begin{array}{c}0.70[0.51-0.95] \\
0.02\end{array}$ \\
\hline $\begin{array}{c}\text { Evolution over } \\
\text { time X } \\
\text { Phase (OLE) } \\
\text { QIC } * *\end{array}$ & $\begin{array}{c}1.32[1.04-1.67] \\
0.02 \\
6205.7717\end{array}$ & 5094.7733 & 5094.7733 & 5969.9733 & 5969.9733 & 5969.9733 \\
\hline $\begin{array}{l}{ }^{*} \text { Results } \\
* * \text { Quasi } \\
{ }^{1} \text { QIC mo } \\
{ }^{2} \text { QIC mo } \\
\text { as explic } \\
{ }^{3} \text { QIC mo } \\
\text { as explic }\end{array}$ & $\begin{array}{l}\text { m the GEE model } \\
\text { relihood under the In } \\
1 \text { with study phases a } \\
1 \text { with study phases a } \\
\text { ve variables: } 5094.80 \\
1 \text { with study phases a } \\
\text { ve variables: } 5975.51\end{array}$ & $\begin{array}{l}\text { endence model Crit } \\
\text { plicative variables: } \\
\text { licative variables: } 5 \\
\text { licative variables: }\end{array}$ & $\begin{array}{l}1.369 ; \text { model witl } \\
.5498 ; \text { model witl } \\
.0632 ; \text { model witl }\end{array}$ & $\begin{array}{l}\text { e and study phases } \\
\text { e, study phases anc } \\
\text { e, study phases anc }\end{array}$ & $\begin{array}{l}\text { plicative variable } \\
\text { nteraction of time } \\
\text { nteraction of time }\end{array}$ & $\begin{array}{l}9.0642 \\
\text { study phases } \\
\text { study phases }\end{array}$ \\
\hline
\end{tabular}

\section{(Continued)}

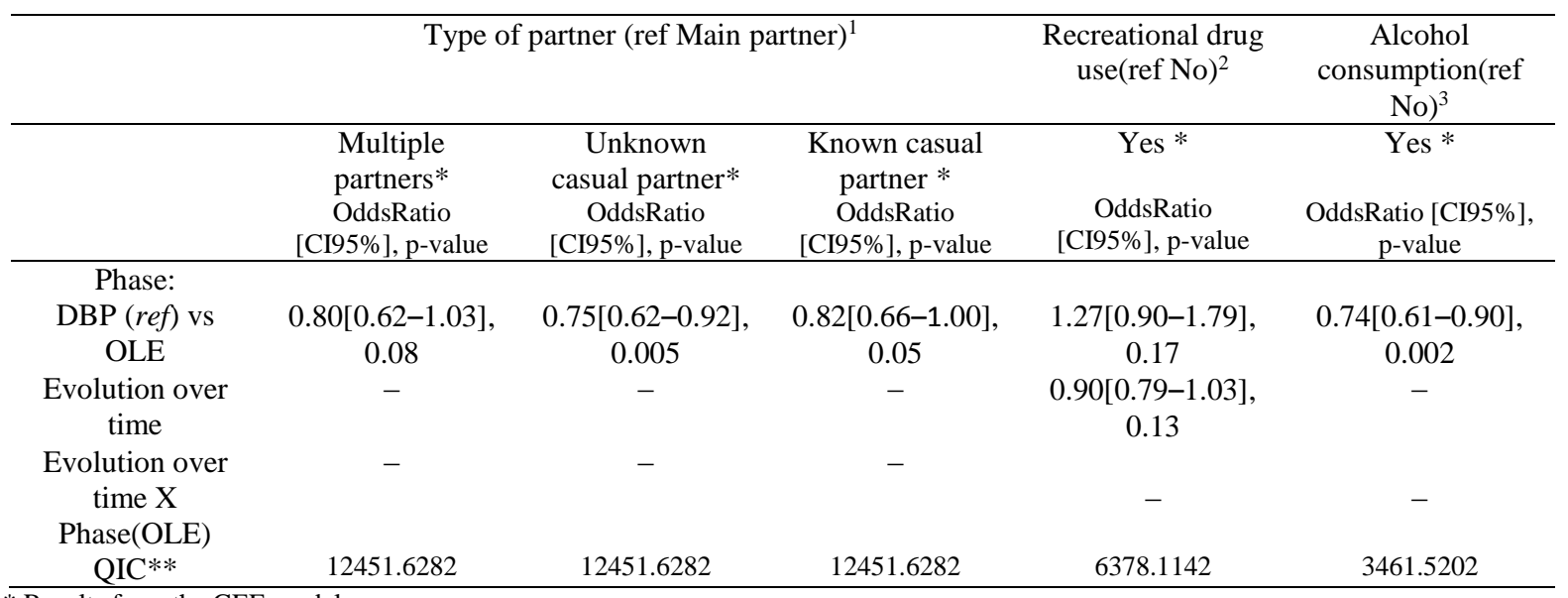

* Results from the GEE model

** Quasi-likelihood under the Independence model Criterion

1 QIC model with time and study phases as explicative variables: 12451.8187 ; model with time, study phases and the interaction of time with study phases as explicative variables: 12457.9333

2 QIC model with study phases as explicative variables: 6378.565; model with time, study phases and the interaction of time with study phases as explicative variables: 6380.2935

3 QIC model with time and study phases as explicative variables: 3463.473 ; model with time, study phases and the interaction of time with study phases as explicative variables: 3465.5496 
